\title{
Estimate of traffic energy consumption from vehicle fleet distribution forecast
}

\author{
Blaž Luin ${ }^{1}$, Fouad Al-Mansour ${ }^{2}$, and Darja $\breve{S}$ emrov $^{3}$ \\ ${ }^{1}$ University of Ljubljana, Faculty of Maritime Studies and Transport, Pot pomorščakov 4, Portorož, \\ Slovenia \\ ${ }^{2}$ Jozef Stefan Institute, Jamova 39, Ljubljana, Slovenia \\ ${ }^{3}$ University of Ljubljana, Faculty of Civil and Geodetic Engineering, Ljubljana, Slovenia
}

\begin{abstract}
Transport policies worldwide foresee electric mobility as a way of mitigating greenhouse gas emissions and energy consumption for transportation. Market forecast scenarios predict different shares of electric vehicles. The paper deals with estimation of energy savings for different scenarios. It will be achieved by defining representative vehicles according to the fleet data and market forecasts and by applying the VSP (Vehicle-Specific Power) based model for microsimulation of traffic scenarios. The application of the methodology that takes into account electric and conventional vehicles will yield traffic energy consumption for different scenarios. Case studies will be presented showing impact of different EV shares and traffic volumes. To simulate the traffic conditions and energy consumption, a microsimulation model SUMO will be used.
\end{abstract}

\section{Introduction}

The focus on environmental protection, lowering of tailpipe emissions and increasing energy efficiency are among the most important goals of traffic policies as transportation is contributing to nearly a third of greenhouse gas emissions (GHG) [1]. The situation is similar in the EU, the US and elsewhere in the world $[2,3]$.

The total GHG emissions from transport sector were $32.4 \%$ of total GHG emissions in Slovenia in 20164 . The GHG emissions from road transportation present more than $99 \%$ of all emissions from transport in Slovenia 4.

Different approaches are being undertaken to minimize traffic emissions, such as modal shift, development of public transport and more energy-efficient power-train technologies. Modal shift is often unsuccessful due to advantages of personal vehicles additionally promoted also by online hailing services in the metropolitan areas due to many possible journey schedules 5 . Electric and hybrid electric vehicles are minimizing the impact of increasing traffic on the emissions and are becoming increasingly popular 6 . Since major share is of the worldwide electricity production comes from fossil fuels, overall emissions may sometimes be comparable to the internal combustion vehicles 7. Study of $\mathrm{CO}_{2}$ emissions of electrical vehicle operation taking into consideration sources of electrical energy concluded that merely shifting to EVs while the electricity source are mainly fossil fuels such as in the case of China and Poland may not bring any reduction of GHG. The importance of increasing the share of renewable sources in the electric grid was also pointed out in a study 
analyzing benefits of EVs in China 8. GHG emissions of electric and plug-in hybrid vehicles during exploitation depends not only on source of electricity from the grid, but also on traffic and environmental conditions where they are used 9.

The VSP (Vehicle Specific Power) model was used to estimate instantaneous power for different internal combustion engine powered vehicles 10 . It is a model that estimates instantaneous power at the wheels on the basis of physical variables, such as speed, acceleration, air drag and road grade. A modified version of the model that in addition to the power at the wheels considered also auxiliary devices power was used to estimate per-trip energy consumption using a traffic microsimulation model. The vehicle energy consumption estimates based on the VSP were used to evaluate energy impact of road construction and traffic management measures 11 . There were other cases of using vehicle power-based models with similar formulation, such as VT-CPFM (Virginia Tech comprehensive Power-based Fuel Consumption Model) which was developed for internal combustion engines and that served as a basis for the VT-CPEM (Virginia Tech comprehensive Power-based Electric Vehicle Energy Consumption Model) [13-15]. It is also based on power at the wheels, that depends on the acceleration, road grade, air drag and rolling resistance parameters that depend on vehicle speed. In comparison to the VSP model, it is not massspecific and has slightly different formulation as due to square of speed term for the rolling resistance.

A backward, power-based model was also applied in a study analyzing impact of different vehicle following models on EV energy consumption [16]. It used a power flow model between the battery and the powertrain. A model for estimation of BEV driving range based on driving trajectories could also be seen as a backward model, although it is not power based, but instead introduces driving distance per state of charge parameter that is fitted to the measured data. There are several speed-based formulations presented and some of them are based on polynomial resembling the VSP model [17].

In this paper, use of traffic microsimulation with vehicle energy consumption model will be used to assess impact of increasing share of electric vehicles on traffic energy consumption. Energy consumption for different scenarios (congested urban, fluent urban, extra-urban) will be simulated.

\section{Overview of traffic forecasts and policies}

Traffic volume estimates can be obtained by forecasting based on various parameters such as current traffic conditions, planned changes in infrastructure, expected demographic and economic changes. Since there can be great amount of input variables, it is sometimes reasonable to use SVR (Support Vector Regression) models for estimating the traffic volume and double exponential smoothing to project future input values.

Since aim of this paper is not to discuss forecasting in-depth, but to evaluate impact of expected traffic EV shares on the total energy consumption, only an overview of the goals will be summarized.

The proposed "Strategy for the development of market for the establishment of appropriate infrastructure related to alternative fuels in the transport sector in the Republic of Slovenia" (Strategy of mobility) 18 foresees an increase in share of passenger electrical vehicles to $20 \%$ of all passenger vehicles by 2030 in the "optimal scenario". The share of electrical passenger vehicles have to be $50 \%$ of all new registered vehicles by 2030 , with $33 \%$ share of batteries electrical vehicles (BEV) and 17\% share of plug-in hybrid electric vehicles (PHEV). The strategy sets a goal for at least 200,000 electric vehicles to be introduced in Slovenia by 2030. The Slovenian government also adopted a decree establishing the infrastructure for alternative transport fuels 19 . 
Slovenian Energy Agency published "Guidelines for the development of electro mobility in Slovenia" 20, The Guidelines foresee achievement of $100 \%$ of electricity mobility in personal and public transport by 2055. The Guidelines predict reduction of GHG emissions by $35 \%$ by 2035 in comparison to 2005 . According to these objectives (and other non-traffic related) by 2035, a halving of the energy use of petroleum products is foreseen, and by 2055 their complete abandonment.

\section{Impact of EVs on traffic energy consumption}

The impact of EVs on traffic energy consumption can be assessed in different ways. This is mainly due to systems that are included in energy conversion analysis. For example, power required at the wheels is virtually the same for cars of similar weight and air drag regardless of power-train. The EVs are very efficient due to braking energy regeneration. To analyze impact of braking energy regeneration, comparison must be made for energy that flows from the battery to the wheels.

To summarize, different energy consumption requirements can be studied:

1. Energy at the wheels. (ATW)

2. Energy at the wheels reduced by regenerated braking energy (ATWR).

3. Energy battery to wheels or tank to wheels (BTW or TTW).

4. Energy well to wheels (WTW).

In this paper an analysis of the energy consumption from the BTW/TTW analysis will be presented in order to assess impact of the increasing shares of EVs in realistic traffic scenarios on the $\mathrm{CO}_{2}$ emissions.

Table 1. Scope of vehicle energy consumption analysis.

\begin{tabular}{|c|c|c|c|c|c|}
\hline Analysis Influence & $\begin{array}{c}\text { mass, drag, } \\
\text { friction }\end{array}$ & $\begin{array}{c}\text { Traffic } \\
\text { conditions, } \\
\text { speed, } \\
\text { acceleration }\end{array}$ & $\begin{array}{c}\text { Braking energy } \\
\text { regeneration }\end{array}$ & $\begin{array}{c}\text { Powertrain } \\
\text { type }\end{array}$ & $\begin{array}{c}\text { electricity } \\
\text { and fuel } \\
\text { production }\end{array}$ \\
\hline $1-$ ATW & $\mathrm{x}$ & $\mathrm{x}$ & & & \\
\hline $2-$ ATWR & $\mathrm{x}$ & $\mathrm{x}$ & $\mathrm{x}$ & & \\
\hline $3-\mathrm{BTW}$ or TTW & $\mathrm{x}$ & $\mathrm{x}$ & $\mathrm{x}$ & $\mathrm{x}$ & \\
\hline $4-$ WTW & $\mathrm{x}$ & $\mathrm{x}$ & $\mathrm{x}$ & $\mathrm{x}$ & $\mathrm{x}$ \\
\hline
\end{tabular}

\section{Model description}

The traffic will be modeled using the SUMO (Simulation of Urban Mobility) traffic microsimulation model in order obtain vehicle trajectories (position, speed) that will be used to estimate energy consumption for different vehicle types using a power-based backward EV model. The backward models estimate power requirement from vehicle kinematic parameters and environmental conditions as they are based on instantaneous acceleration, speed, road grade and depend on friction and rolling resistance coefficients. The output of the model is instantaneous energy consumption that is used to estimate either power consumed from the fuel or the battery. The vehicle specific power (VSP) model is defined as

$$
V S P=C_{1} v a+g k v+C_{2} v+C_{3}\left(v+v_{w}\right)^{2} v
$$


where $C_{1}, C_{2}$ and $C_{3}$ are constants that depend on acceleration losses, rolling and internal resistance and air drag. The model for simulation of EV energy flow is described and evaluated in the paper 9 . The parameters for simulation are based on the assumptions shown in the table 2 .

Table 2. Characteristic vehicle parameters for simulation.

\begin{tabular}{|c|c|c|c|c|c|}
\hline & \multicolumn{3}{|c|}{ Passenger vehicles } & \multicolumn{2}{c|}{ BUS } \\
\hline parameter & IC & hybrid & BEV & hybrid & IC \\
\hline $\mathrm{C}_{1}$ & 1.17 & 1.17 & 1.17 & 1.1 & 1.1 \\
\hline $\mathrm{C}_{2}$ & 0.070 & 0.070 & 0.070 & 0.092 & 0.092 \\
\hline $\mathrm{C}_{3}$ & 0.00028 & 0.00028 & 0.00028 & 0.000127 & 0.000127 \\
\hline$\eta_{\mathrm{e}}$ & 0.2 & 0.2 & $/$ & 0.2 & 0.2 \\
\hline$\eta_{\mathrm{p}}$ & $/$ & 0.75 & 0.75 & 0.75 & $/$ \\
\hline$\eta_{\mathrm{c}}$ & $/$ & 0.95 & 0.95 & 0.95 & $/$ \\
\hline $\mathrm{m}[\mathrm{kg}]$ & 1400 & 1500 & 1590 & 18000 & 17000 \\
\hline battery capacity $[\mathrm{kWh}]$ & $/$ & 5 & 25 & 19 & $/$ \\
\hline
\end{tabular}

\section{Microsimulation results}
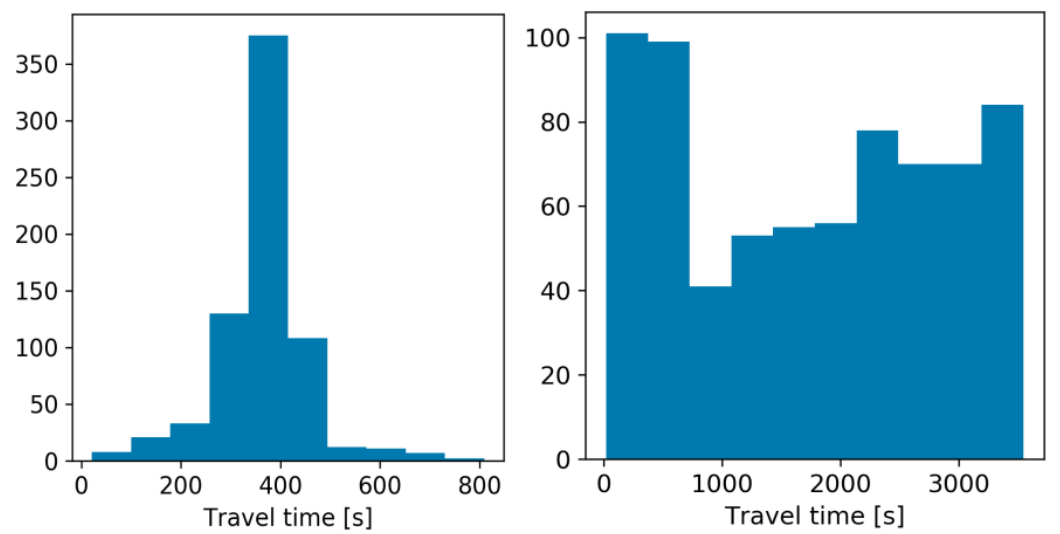

Fig. 1. Vehicle travel times distribution for scenarios 1 (left) and 2 (right).

In the first run of simulations, an urban traffic case was simulated in fluent (scenario 1) and in congested states (scenario 2) to assess the impact of increased EV share on the overall energy consumption. The simulations were repeated using the shares of electric vehicles between 0 and $80 \%$. For each case overall energy consumption was evaluated. From the Figure 2 it is evident that the overall energy consumption is decreasing linearly with the increasing share of EVs. 


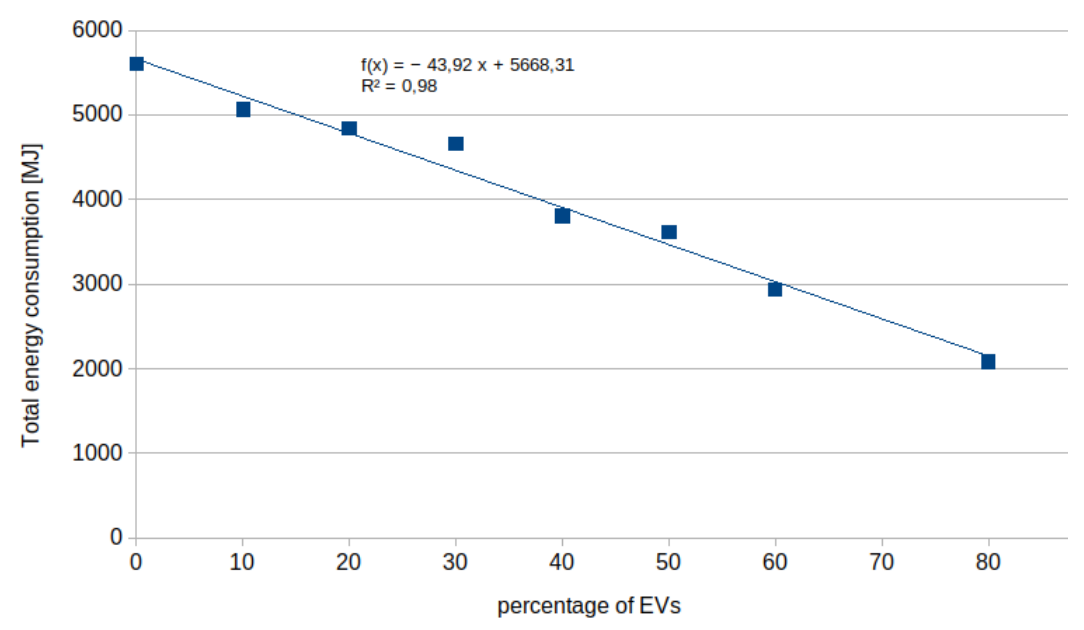

Fig. 2. Total energy consumption per cycle. Scenario $1.7 \% \mathrm{HEV}$.

As it can be seen in the Figures 2-4, much greater energy savings can be obtained when traffic is congested and there is more stop-and-go events. This has also evident in the Figure 1, where distribution of travel times has a lot higher frequency of long travel times in case of congested scenario 2. According to the Slovenia's target for 2030, the $20 \%$ share of EVs in the fleet is expected to bring about $12 \%$ (congested traffic) to $17 \%$ (flowing traffic) total energy consumption reduction for city traffic.

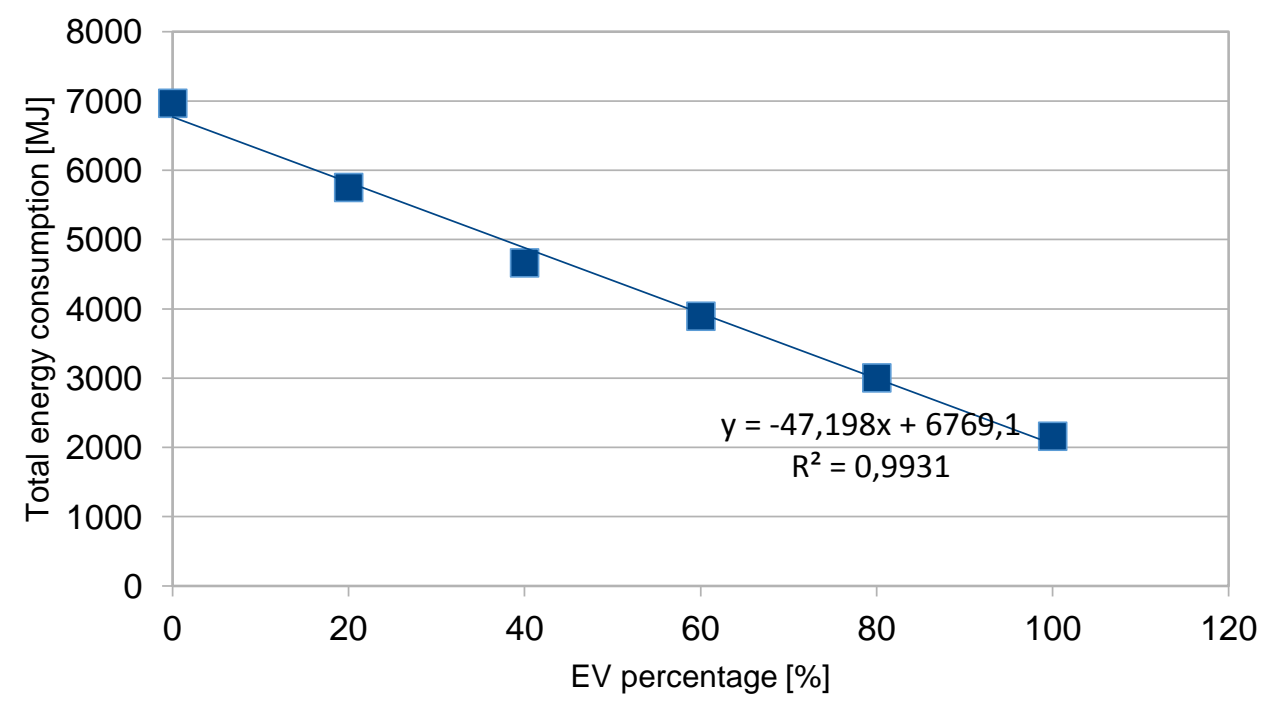

Fig. 3. Total energy consumption per cycle. Scenario 1. No HEV. 


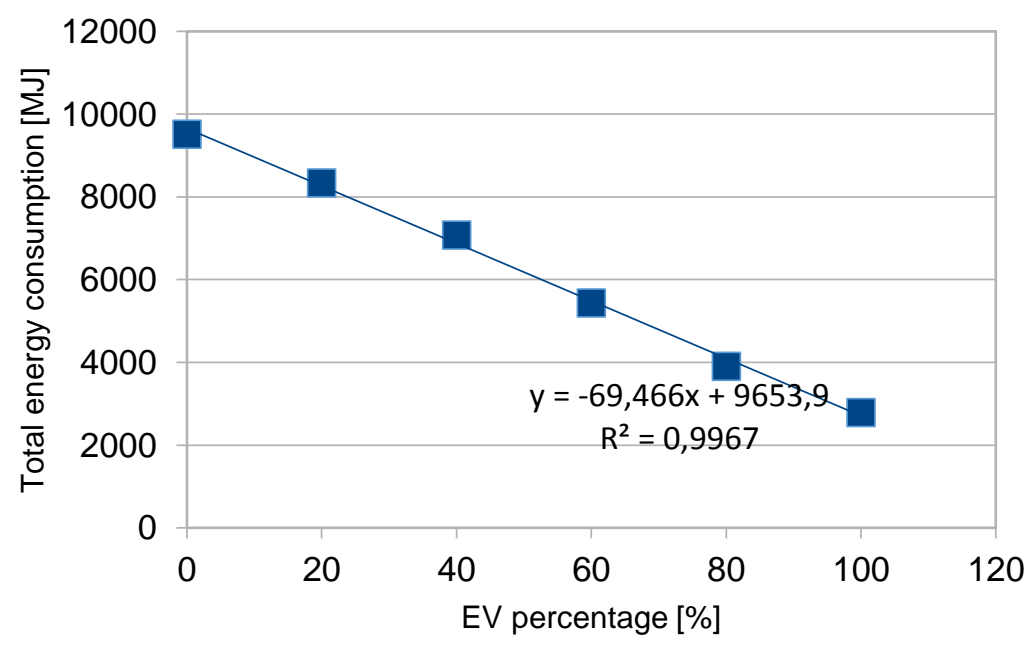

Fig. 4. Total energy consumption per cycle. Scenario 2. No HEV. Congested.

\section{Conclusion and discussion}

Use of traffic microsimulation coupled with EV energy flow model is demonstrated for estimation of impact of increasing share of EVs on overall traffic energy consumption. The simulations were carried out only for city traffic under different traffic conditions (fluent and congested). Absolute energy savings were higher for congested traffic, but relative lowers were slightly lower, $12 \%$ compared to $17 \%$ for fluent traffic.

On the other hand, it should be noted that the simulation scenarios covered only specific traffic cases and cannot yet be generalized to a wider set of conditions. Additional simulations that would include freeway traffic, different terrain configurations and weather (temperature) conditions should be analyzed in order to draw more general conclusions.

\section{References}

1. Commission E-E. Roadmap to a Resource Efficient Europe. COM 571 (2011)

2. N. Bianco, F. Litz, Reducing greenhouse gas emissions in the United States using existing federal authorities and state action (The World Resources Institute, $10 \mathrm{G}$ Street, NE Suite 800 Washington, D. C. 20002 USA, 2010)

3. G. Fontaras, N. G. Zacharof, B. Ciuffo, Progress in Energy and Combustion Science 60, 97-131 (2017)

4. Slovenian environmental agency (ARSO), Slovenia's National Inventory Report 2018: GHG emissions inventories 1986-2016, submitted under the United Nations Framework Convention on Climate Change, Ljubljana (2018)

5. T. Wu, Q. Shen, M. Xu, T. Peng, X. Ou, Energy 154, 298-307 (2018)

6. J. S. Chen, Energies 8, 4697-723 (2015)

7. IEA $\mathrm{CO}_{2}$ Emissions from Fuel Combustion Statistics n.d. 
8. A. R. Gopal, W. Y. Park, M. Witt, A. Phadke, Transportation Research Part D: Transport and Environment 62, 362-71 (2018)

9. B. Luin, S. Petelin, F. Al-Mansour, Energy 174, 24-32 (2019)

10. H. Zhai, H. C. Frey, N. M. Rouphail, Environ Sci. Technol. 42, 7985-91 (2008)

11. J. L. Jiménez-Palacios, Understanding and quantifying motor vehicle emissions with vehicle specific power and TILDAS remote sensing (Thesis, Massachusetts Institute of Technology, 1999)

12. B. Luin, S. Petelin, F. Al Mansour, Energy 137, 260-71 (2017)

13. S. Park, H. Rakha, K. Ahn, K. Moran, International Journal of Transportation Science and Technology 2, 317-36 (2013)

14. C. Fiori, K. Ahn, H. A. Rakha, Transportation Research Part D: Transport and Environment 63, 175-85 (2018)

15. C. Fiori, K. Ahn, H. A. Rakha, Applied Energy 168, 257-68 (2016)

16. S. Yang, C. Deng, T. Tang, Y. Qian, Nonlinear Dynamics 71, 323-9 (2013)

17. J. Bi, Y. Wang, Q. Sai, C. Ding, Energy 169, 833-43 (2019)

18. Minstrstvo za infrastrukturo: Strategija na področju razvoja trga za vzpostavitev ustrezne infrastrukture $\mathrm{v}$ zvezi $\mathrm{z}$ alternativnimi gorivi v prometnem sektorju $\mathrm{v}$ Republiki Sloveniji, Predlog, Maj 2017, https://e-uprava.gov.si/.download/edemokracija/datotekaVsebina/298735?disposition=i nline

19. Decree establishing the infrastructure for alternative transport fuels, Official gazette of RS, 41 (2017)

20. Agencija RS za energijo: Smernice za razvoj elektromobilnosti v sloveniji/Guidelines for the development of electromobility in slovenia, 01.02.2017, https://www.agenrs.si/documents/10926/26021/ 